\title{
The role of individual personality in conceptualizing and measuring group characteristics
}

\author{
Marius Deckers ${ }^{1} \cdot$ Tobias Altmann $^{1} \cdot$ Marcus Roth $^{1}$ \\ Published online: 13 July 2020 \\ (C) The Author(s) 2020
}

\begin{abstract}
In previous research, group characteristics have often been measured without taking the individual perspective of the group members into account. Therefore, the influence of individual personality (and other individual-level characteristics) on group characteristic ratings beyond the influence of the actual group remains largely unexplored. Additionally, some studies use group means of individual personality as group characteristics, however, evidence for interrelations or differences between these approaches has not yet been empirically based. In the present study, we employed a sample of 301 individuals from 54 teams, all of which rated both characteristics of themselves and their teams. By averaging both self-ratings and group-ratings within each team, we were able to compare both approaches to group characteristics and found them to likely measure unrelated constructs. We also found influences of individual Extraversion and Agreeableness from the HEXACO model on direct group characteristic ratings beyond the influence of the actual group. Years of work experience and work strain operationalized through burnout symptoms did not predict group characteristic ratings beyond the influence of the actual group and individual personality. Our findings imply that individual ratings of a group characteristic are influenced to a larger degree by the raters' individual perspectives than by the presumed actual group characteristic itself. Further implications for research applying individual personality to groups are discussed.
\end{abstract}

Keywords Personality $\cdot$ HEXACO $\cdot$ Group $\cdot$ Cohesion $\cdot$ Openness $\cdot$ Climate

\section{Introduction}

Individual personality characteristics, such as extraversion or neuroticism, represent stable behavioral patterns of perceiving the world and interacting with it. Trait scores on personality dimensions such as the Big Five (McCrae and Costa Jr. 1999) or dimensions of the HEXACO model (Ashton and Lee 2007) have been shown to influence general lifestyle choices and

The datasets generated during and/or analyzed during the current study are available from the corresponding author on reasonable request.

Marius Deckers

marius.deckers@uni-due.de

Tobias Altmann

tobias.altmann@uni-due.de

Marcus Roth

marcus.roth@uni-due.de

1 Department of Differential Psychology, University of Duisburg-Essen, Universitätsstraße 2, 45141 Essen, Germany aspirations (Visser and Pozzebon 2013), as well as general worldviews and attitudes (Leone et al. 2012).

When individuals rate characteristics of themselves, great care is usually taken to ensure the validity of these self-reports. Normally, self-reports in which individuals rate their usual ways of behaving and experiencing are not simply relied on, and the validity of such self-reports is often determined through multiple other criteria, such as by their consensus with peer-reports, by their ability to predict actual behavior, or through correlation with socially desirable response styles. However, when individuals rate characteristics of a group they belong to, it is assumed that these group ratings are valid representations of group characteristics, i.e., that individuals are able to reliably and validly rate characteristics of their actual group (for examples, see: Anderson and West 1998; Bjornberg and Nicholson 2007).

As a result of this assumption, the role of the individual perspective and what it is influenced by aside from the actual group is usually forgone and there is a lack of research on how individual personality (and other individual characteristics) predict how individuals perceive and rate characteristics of groups they belong to. An examination of this influence is 
rather important, as both its extent and its mechanics are unknown, and the finding of a large extent of influence would call the implicit assumption of valid group characteristic ratings by group members into question in a few ways. Such a finding would imply that group characteristics might have to be conceptualized and measured differently than they are now. This is especially relevant for research trying to establish connections between group characteristics rated by the group members and other group-level constructs such as work performance or problem solving, as such connections rely on group characteristic ratings being reliable and valid in the first place.

Our study is also relevant for all research that involves group personality composition and the calculation of group means across individual member characteristics, which is very common (Barrick et al. 1998), as we will outline both theoretical and potential practical shortcomings of this approach. Finally, this study challenges the validity of the also very common measures of group characteristics that rely on group members rating these characteristics (e. g. Anderson and West 1998) and the usage of averages of those ratings per team. We were able to show that individual members' ratings of group characteristics are influenced to a considerable degree by factors beyond the influence of the actual group and its presumed latent characteristics.

In our research, we analyze group-level and individuallevel influences on group characteristic ratings separately, which are usually difficult to separate at all, because a difficult-to-achieve sample collection and study design is required. In doing so, we will also examine the common approach of calculating group means of individual member personality traits.

\section{Measuring Psychological Group Characteristics}

In past research, group characteristics have been conceptualized and measured through what we label either an indirect or a direct approach. Both will be explained in detail below.

\section{The Indirect Approach}

Group characteristics are sometimes conceptualized as composites that can be calculated or inferred from the individual characteristics of the group members. This approach commonly employs the individual personality trait scores of the group members to calculate group averages for each trait, treating those means as characteristics of the group (e.g., Barrick et al. 1998; Dang and Ilgen 2006). This approach usually employs group means in the dimensions of the Five Factor Model (McCrae and Costa Jr. 1999) (e.g., Barrick et al. 1998; Halfhill et al. 2005a; Homan et al. 2008; Neuman et al. 1999; van Vianen and De Dreu 2001). The typical areas of interest that this approach is used in are work teams and their performance (Barrick and Mount 1991; Homan et al. 2008).

In studies using this indirect approach employing the Five Factor Model, individual personality traits applied to the group have been unable to consistently predict outcomes such as group performance (Barrick et al. 1998; Barry and Stewart 1997; Bond and Shiu 1997; Halfhill, Nielsen, et al., 2005; Neuman et al. 1999; van Vianen and De Dreu 2001). Group performance is usually operationalized through task completion speed and accuracy and usually rated by a supervisor. These findings are summarized in two meta-analyses with an overlap of only eight studies (Bell 2007; Peeters et al. 2006). Apart from group mean conscientiousness with small or small to medium effects (according to Cohen 1992), these meta-analyses report different results for the influence of the group means in the Big Five traits on group performance. Even these two meta-analyses (concerned with the same phenomenon but citing mostly different studies) arrive at different conclusions, highlighting the inability of group-level means of individual personality to predict group performance specifically. These findings are to some extent in line with metaanalyses concerned with Big Five characteristics and job performance on the individual level (Barrick and Mount 1991; Hurtz and Donovan 2000), in which only individual conscientiousness and emotional stability emerged as generalizable predictors; however, in our opinion, individual personality applied to the group level through group means should be treated as a different domain, which will be explained below.

To our knowledge, there is no theoretical justification or empirical evidence to support the assumption that individuallevel traits can be applied to the group in such a way and that personality traits applied to the group can be treated as conceptually the same as at the individual level (the fact that extraversion has been established as an individual-level trait does not imply that extraversion is also necessarily a grouplevel trait). In his article on group composition typology, Chan (1998) voices a similar concern: When individual characteristics are aggregated at the group level, a composition theory that specifies the supposed relationship between the individual-level and the group-level constructs is of critical importance to present a substantive meaning for the group mean. Chan also explains that this need for a composition theory remains true even for constructs where consensus within the group is not necessary or logical, which is the case when individual personality traits are averaged within the group. To our knowledge, such a composition theory for individual personality traits applied to the group-level has not been given so far. There also appears to be no rationale for how to choose the specific method for calculating a group trait score from individual scores. A simple group mean score might be just as plausible or implausible as extremity-weighted means (e.g., Halfhill et al. 2005b) or variability measures (e.g., Homan et al. 2008). 
For these reasons, the relation between individual group members' personalities and the group's characteristic has been up for debate, and the indirect approach to measuring group characteristics using individual-level personality scores has been criticized (Chan 1998; Dang and Ilgen 2006; Shoda et al. 2002).

\section{The Direct Approach}

In the direct approach to measuring psychological group characteristics, each group member rates their group's characteristic by rating their group's behavioral tendencies (e.g., "I believe that the team is open to changes" or "There is mutual trust in our team"). The group mean score of these ratings is then used as a characteristic on the respective dimension (for examples, see: Anderson and West 1998; Bjornberg and Nicholson 2007).

There are multiple conceptualizations of group traits using the direct approach, often under the label of group climate (Hellriegel and Slocum 1974). Group climate has been researched in different types of groups, such as work teams (Anderson and West 1998), families (Bjornberg and Nicholson 2007; Roth 2002), therapy groups (Law et al. 2012; MacKenzie and Tschuschke 1993), and sports groups (Carron et al. 1985; Eys et al. 2009).

Most group climate conceptualizations so far have been created primarily for specific types of groups, which makes it difficult to compare results of multiple studies using different types of groups. Therefore, a more universal group characteristic concept has been introduced by Deckers et al. (2018) with the dimensions group openness and cohesion. Here, group openness is conceptualized as a generalized outward orientation of the group (i.e., how the group views and reacts to outside influences such as new members or other new impulses), whereas cohesion is conceptualized as a generalized inward orientation of the group (i.e., mutual support and affection between the group members). This group characteristic structure is conceptualized as applicable to various types of groups.

Numerous studies have explored group characteristics such as cohesion or within-group support as either predictors or outcomes of other group-level phenomena, such as group productivity or success (Carron and Spink 1995; Cheng et al. 2016; Evans and Dion 2012; Goh et al. 2009; Gully et al. 2012; MacKenzie and Tschuschke 1993; Widmeyer et al. 1990). There is also a substantial body of literature on the influence of group-level characteristics on individual-level outcomes such as job satisfaction or social adjustment (Dackert 2010; Glisson and James 2002; Kivimaki et al. 2007; Kurdek et al. 1995). There is also research on how individual-level traits, such as personality, influence how individuals perceive groups they are not part of. Much of this research is concerned with prejudice and intergroup conflict (for examples, see: Ekehammar et al. 2004; Turner et al. 2014). The influence of individual traits on out-group attitudes is understandably deemed important to understand how outgroup attitudes and prejudice are formed and how they can often be very far from the truth.

However, when individuals rate their own group, they are essentially treated as experts capable of valid group characteristic ratings: In comparison to the above research endeavors, the literature on how individual personality traits (and other individual-level traits) predict how individuals perceive and rate their own group is practically non-existent. Overall, differences in ratings between individuals in the same group are often neglected when these individuals rate their group (they are essentially voided and treated as measurement error when group means are calculated). Most studies are not designed in a way that allows for the separation of individual-level and group-level influences on how individual members perceive and rate their group, because studies with both multiple groups and multiple members per group rating the same characteristics are rare, as they require a difficult sampling process. Therefore, how individual personality characteristics and other individual-level traits influence how individuals perceive and rate their own group remains largely unexplored in the literature.

\section{Research Goals}

We had two research goals. First, we wanted to examine how the two approaches to measuring group characteristics are interconnected. We therefore examined the extent to which the group-level scores obtained by applying the indirect approach (the group average of individual personality selfratings) would predict the group-level scores obtained by applying the direct approach (the group average of group characteristic ratings). Given that there is no inventory that can be used to assess both approaches assessing the same dimensions, we operationalized the indirect and direct approach by using two different inventories, as it has been done in previous research assessing the respective individual and group characteristics (for details, see Method section). Of course, differences between the two inventories include the specific item content and subscales. This problem will be discussed in detail in the discussion.

Second, we had specific expectations about which individual traits are related to the way individuals perceive and rate their groups' characteristics. As individual personality traits describe a general tendency to perceive and interact with the world, they can reasonably be assumed to influence how a person perceives and rates his or her own group independently from the actual characteristics of that group. In recent years, the HEXACO model of personality (Ashton and Lee 2007) has been established as an alternative to the Five Factor Model (FFM; McCrae and Costa Jr. 1999). It proposes six basic 
personality dimensions recovered from the personality lexicons of various languages (Lee and Ashton 2008). Whereas the dimensions Extraversion, Openness, and Conscientiousness are similar to the corresponding FFM dimensions, the dimensions Emotionality and Agreeableness are only moderately correlated with the corresponding FFM dimensions (e.g., Ashton and Lee 2009). In the HEXACO alignment, high Emotionality is a combination of low Emotional Stability and high Agreeableness, and high HEXACO Agreeableness is a combination of high Big Five Agreeableness and high Emotional Stability. The additional HEXACO dimension Honesty-Humility, which contains fairness and sincerity versus greed and conceit, has no direct counterpart in the FFM, but its highest correlation is with agreeableness from the FFM (Ashton and Lee 2008a, 2008b). The HEXACO model explains additional variance in personality compared to multiple Big Five inventories. As shown by Ashton and Lee (2019), multiple Big Five inventories are lacking in at least one aspect captured by the HEXACO model. The HEXACO model can therefore be seen as a more complete operationalization of personality, which is why we employed it in this study. Especially the more "social" traits of the HEXACO model, agreeableness and extraversion, are likely to influence group perceptions. Besides the HEXACO dimensions, we found years of working experience and work strain as additional likely predictors in the literature. Age has been shown not to affect group cohesion ratings (Glass and Benshoff 2002); we therefore wanted to examine whether this finding could be replicated using years of work experience as a predictor. Work strain (operationalized as burnout symptoms) has been shown to negatively affect judgments of the self and others (Durkin et al. 2016). It was therefore possible for work strain to affect an individual's perception of his or her (work) team as well.

In summary, we hypothesized the group means of the indirect approach to not significantly predict the group means of the direct approach, as outlined in our explanations for the theoretical issues with the indirect approach. We also hypothesized individual direct ratings of group characteristics to be significantly influenced by individual agreeableness and extraversion and by perceived work strain but not by years of working experience beyond the influence of the actual group characteristics.

\section{Method}

\section{Sample, Data Structure, and Procedure}

The sample for this study consisted of nurses organized in distinct teams in university hospitals. This specific sample was chosen because it was part of a larger research project, and team assignment is very distinct in nursing. The latter ensures that, when individuals rate the characteristics of their team, they have a clear picture of which group exactly they are rating. This provided a hierarchical data structure. Overall, 389 individuals participated in the study. We excluded teams in which fewer than four members participated in the study to ensure that calculating the means for each team would be meaningful. For the teams excluded in this way, the three or less team members representing their teams only formed an average of $8,71 \%$ of their team. This further justified their exclusion, as this percentage fell substantially below the percentage of representation in the non-excluded teams, from which we recruited an average of $25.97 \%$ of members per team. Team size ranged from seven to 71 members, with a mean team size of 26.6 members. The final sample consisted of 301 nurses from 54 different teams (80.5\% women, $18.8 \%$ men, $0.7 \%$ did not indicate their gender). The age range in the sample was 20 to 61 years $(M=37.5, S D=11.2)$. The range of years the participants had been working in nursing for was 1 to 42 years $(M=16.0, S D=10.45)$. In order to ensure valid ratings of group characteristics, we also assessed the time for which participants had been part of their team. Membership time ranged from 0.25 to 36 years $(M=6.9, S D=6.86)$, median membership time was 4 years, and distribution of membership time was skewed, with a kurtosis of 2.667 and $65 \%$ of values being lower than the mean. Overall, only $3.7 \%$ of the sample had been with their team for less than 1 year.

Participants were recruited from four university hospitals in Germany (Cologne, Bonn, Essen, and Düsseldorf). They filled out all instruments employed in this study, along with items for demographic data, during normal working hours. All participants were informed about the purpose of this study in written form explaining that this study was part of a larger research project on psychological strain in nursing and its antecedents (both weakening and favoring) and development over time. All participants provided informed consent and participated voluntarily.

Data collection was done on set dates with all members of the team who were assigned to this work shift, which essentially ensured a random sampling per team, as the shift plans can be seen as largely random. This circumvents a potential selection bias. None of the participants selected in this way declined or withdrew from participation.

\section{Operationalizations and Measures}

All instruments used in this study were in the German language.

\section{Individual Personality and Group Characteristics Obtained with the Indirect Approach}

To measure individual personality, we administered the German translation of the 60-item version of the HEXACO- 
PI-R (Ashton and Lee 2009) by Ashton et al. (2007), which contains the dimensions Honesty-Humility (item example: "If I knew that I could never get caught, I would be willing to steal a million dollars"), Emotionality (item example: "I worry a lot less than most people do"), Extraversion (item example: "I rarely express my opinions in group meetings"), Agreeableness (item example: "People sometimes tell me that I am too critical of others"), Conscientiousness (item example: "I make decisions based on the feeling of the moment rather than on careful thought"), and Openness to Experience (item example: "I would be quite bored by a visit to an art gallery"). Cronbach's alpha for the HEXACO-PI-R subscales was acceptable (Honesty-Humility $\alpha=.68$, Emotionality $\alpha=.74$, Extraversion $\alpha=.62$, Agreeableness $\alpha=.66$, Conscientiousness $\alpha=.68$, Openness to Experience $\alpha=.71$ ). All 6 dimensions were rated on a five-point Likert scale from 1 to 5. The response anchors were worded as the German equivalent to "strongly agree", "agree", "neutral (neither agree nor disagree)", "disagree", and "strongly disagree". The HEXACO-model is an alternative to the Five Factor Model of personality (Ashton and Lee 2007; McCrae and Costa Jr. 1999), which captures individual personality as completely as possible, while still being close enough to the Big Five to enable comparisons between the present study and previous studies employing the indirect approach.

Group characteristic scores obtained with the indirect approach were also calculated using the team members' individual HEXACO scores, meaning that each team was assigned a team-mean score for each of the six HEXACO dimensions.

\section{Group Characteristics Obtained with the Direct Approach}

Using the direct approach, group characteristics were measured with the Group Openness and Cohesion Questionnaire (GOCQ; Deckers et al. 2018). The GOCQ asks the individual to rate his or her entire group/team on seven items that measure Group Openness and 10 items that measure Cohesion (example item for Group Openness: "New ideas are considered in our team"; for Cohesion: "In our team, we have a 'we're all in the same boat' attitude"). Cronbach's alpha was good (Group Openness $\alpha=.90$, Cohesion $\alpha=.91$ ). Both dimensions were rated on a five-point Likert scale from 1 to 5 with the response anchors being worded the German equivalent to "totally agree", "mostly agree", "somewhat agree", "agree a little bit", and "do not agree at all".

\section{Work Strain}

Work strain was operationalized as burnout symptoms and measured with the Copenhagen Burnout Inventory (CBI; Kristensen et al. 2005), which differentiates between three sources attributed to the burnout symptoms: Personal Burnout (six items, $\alpha=.87$ ), Work-Related Burnout (seven items, $\alpha=.86$ ), and Client-Related Burnout (six items, $\alpha=$.78). All three dimensions were rated on a five-point Likert scale from 0 to 4 , as the authors recommended, with the response anchors being the same as for the GOCQ. A German translation of the CBI was created specifically for this study and its content equivalence was confirmed by native speakers of the German and English languages.

\section{Results}

Means and standard deviations of all used variables, along with their intercorrelations, are summarized in Table 1.

\section{Comparing the Group Mean Scores from the Two Approaches}

To assess the extent to which the two approaches for measuring group characteristics measured similar constructs, we ran two linear multiple regression analyses using the aggregated team-level means of the HEXACO dimensions as the predictors and the team-level means of the GOCQ dimensions Group Openness and Cohesion as the respective outcomes. The results, based on 54 teams, are presented in Table 2.

Table 2 shows that group mean Emotionality was a significant positive predictor of group mean Cohesion, and all other $\mathrm{B}$ and $\beta$ weights were nonsignificant. The overall regression model for group mean Group Openness was significant $(F(6$, $47)=2.418, p<.05$ ), while the overall regression model for group mean Cohesion was not significant $(F(6,47)=2.229$, $p=.057)$. The adjusted $R^{2}$ showed that $13.8 \%$ of the variance in the group means in the Group Openness scale and $12.2 \%$ of the variance in the group means in the Cohesion scale were explained by the group means of the individual personality dimensions. In combination with the nonsignificant $B$ and $\beta$ weights, these small $R^{2}$ values are likely to be a product of chance instead of an indication of an actual connection in the population. Further evidence towards this is given by the fact that the only significant prediction was part of a model that failed to reach overall significance.

\section{Predicting Individual Ratings of Group Characteristics from Other Constructs}

Intraclass-Correlation-Coefficients (ICCs) for Group Openness and Cohesion revealed that $23 \%$ of the variance in Group Openness ratings and 37\% of the variance in Cohesion ratings was variance at the group-level, respectively. These variance components are too low to conclude that the response patterns in the instrument GOCQ are only or even primarily influenced by a latent group characteristic structure. The amount of individual-level variance in these response patterns 


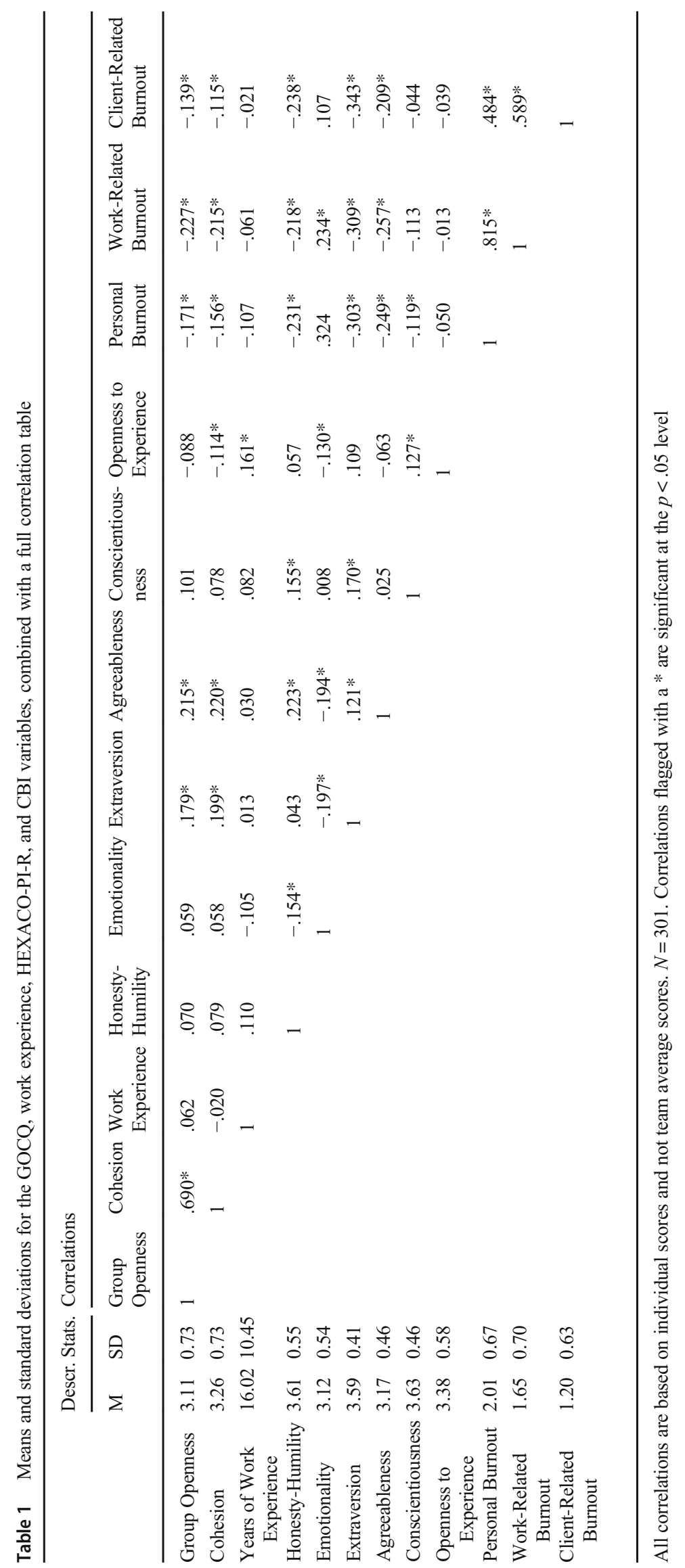


Table 2 Linear multiple regression analysis with the group-level means of the HEXACO dimensions as predictors of group-level ratings of group openness (left) and cohesion (right)

\begin{tabular}{|c|c|c|c|c|c|c|c|c|c|c|c|c|}
\hline & \multicolumn{6}{|c|}{ Group Mean Group Openness Ratings } & \multicolumn{6}{|c|}{ Group Mean Cohesion Ratings } \\
\hline & B & SE (B) & $\beta$ & $p$ & $R^{2}$ & Adj. $R^{2}$ & B & $\mathrm{SE}(\mathrm{B})$ & $\beta$ & $p$ & $R^{2}$ & Adj. $R^{2}$ \\
\hline Constant & -0.039 & 1.998 & & .985 & .236 & .138 & -0.477 & 2.165 & & .827 & .221 & .122 \\
\hline Group mean Honesty-Humility & 0.462 & 0.270 & 0.244 & .094 & & & 0.290 & 0.293 & 0.142 & .327 & & \\
\hline Group mean Emotionality & 0.168 & 0.223 & 0.109 & .457 & & & 0.505 & 0.242 & 0.306 & .043 & & \\
\hline Group mean Extraversion & 0.522 & 0.300 & 0.251 & .089 & & & 0.650 & 0.325 & 0.291 & .051 & & \\
\hline Group mean Agreeableness & 0.377 & 0.340 & 0.168 & .273 & & & 0.346 & 0.369 & 0.144 & .353 & & \\
\hline Group mean Conscientiousness & -0.171 & 0.303 & -0.080 & .575 & & & -0.258 & 0.329 & -0.113 & .437 & & \\
\hline Group mean Openness to Experience & -0.446 & 0.225 & -0.275 & .054 & & & -0.412 & 0.244 & -0.237 & .098 & & \\
\hline
\end{tabular}

Group-level analysis with $N=54$ teams

is substantial, which means that individual ratings of the group are likely influenced by other individual characteristics as well.

We used hierarchical regression analyses to find the incremental predictive contribution in explained variance of each dimension beyond the influence of the actual group. A method to exclude the influence of the actual group (characteristics) from the individual self-reported group characteristic ratings was needed, which we achieved as follows: As the best available proxy for the characteristics of the actual group, we calculated a new variable that assigned the mean team characteristic ratings to each individual but from which the respective individual was excluded. As an example, for a team with four members, Member A was assigned the means of Group Openness and Cohesion ratings of Members B, C, and D, and the same procedure was applied to Members B, C, and $\mathrm{D}$, respectively. Using this variable in the first step of the hierarchical regression analysis allowed us to exclude the group-level variance component (representing the influence of the actual group) in the first step, so that all subsequent steps used only the remaining individual-level variance in the dependent variable. Evidence for the success of this method is given by the fact that more variance was explained in this step for the variable with the higher ICC (Cohesion), as a higher ICC shows greater grouplevel influence.

After this step, the second predictor entered into the hierarchical regression was years of working experience, as we had no reason to expect any significant prediction through this factor, especially of variance that is explained by the other factors, as years of working experience only had a small significant correlation with openness to experience (see Table 1), which was by itself unlikely to contribute significantly to group characteristic ratings. The third step included individual personality, as this was our primary focus and has the broadest applicability of our research to other research involving group characteristic ratings in other domains. The inclusion of burnout symptoms was the final step. From the literature, we expected its contribution to the explained variance to be small, and we were interested in the effects of burnout symptoms beyond personality, which was our main focus. Personality is applicable to all human beings and therefore to all cases where individual group members rate characteristics of their group, while burnout is very likely specific to the sample used for this study. Therefore, using this order for the predictors somewhat strengthened generalizability. However, the alternative order for entering these last two predictors was equally justifiable, with burnout symptoms being used as a control variable before the influence of personality. We therefore performed additional analyses with this order, which did not affect the results in any substantial way.

Years of work experience, individual personality, and burnout symptoms were entered as predictors in subsequent steps in the hierarchical regression analyses. Tables 3 and 4 show the results for Group Openness and Cohesion, respectively.

Individual ratings of both Group Openness and Cohesion were significantly influenced by individual personality, specifically by Extraversion and Agreeableness values, with those predictions being positive. The other four HEXACO dimensions were not significant predictors. Years of work experience and burnout symptoms did not explain a significant amount of variance in group characteristic ratings beyond the other constructs. The results were the same for the Group Openness and Cohesion ratings concerning the significance of the predictors. The overall regression model for Group Openness ratings was significant $(F(11,289)=6.365, p<.001)$, as was the overall regression model for Cohesion ratings $(F(11,289)=$ $13.306, p<.001)$. Further analyses with the order of the last two steps switched did not provide different results. 
Table 3 Hierarchical regression analysis with the individual rating of group openness as the dependent variable

\begin{tabular}{|c|c|c|c|c|c|c|c|c|c|c|c|c|c|c|c|c|c|}
\hline & \multicolumn{4}{|l|}{ Step 1} & \multicolumn{4}{|l|}{ Step 2} & \multicolumn{4}{|l|}{ Step 3} & \multicolumn{4}{|l|}{ Step 4} & \multirow[b]{2}{*}{$r_{c p}$} \\
\hline & $\mathrm{B}$ & $\mathrm{SE}(\mathrm{B})$ & $\beta$ & $p$ & $\mathrm{~B}$ & $\mathrm{SE}(\mathrm{B})$ & $\beta$ & $p$ & $\mathrm{~B}$ & $\mathrm{SE}(\mathrm{B})$ & $\beta$ & $p$ & B & $\mathrm{SE}(\mathrm{B})$ & $\beta$ & $p$ & \\
\hline Intercept & 1.555 & 0.272 & & .000 & 1.482 & 0.279 & & .000 & -0.723 & 0.682 & & .290 & -0.398 & 0.771 & & .606 & \\
\hline $\begin{array}{l}\text { Group Openness } \\
\text { ratings } \\
\text { (self excluded) }\end{array}$ & 0.500 & 0.087 & 0.316 & .000 & 0.500 & 0.087 & 0.316 & .000 & 0.433 & 0.085 & 0.274 & .000 & 0.420 & 0.086 & 0.265 & .000 & .316 \\
\hline $\begin{array}{l}\text { Years of Work } \\
\text { Experience }\end{array}$ & & & & & 0.004 & 0.004 & 0.064 & .244 & 0.005 & 0.004 & 0.074 & .172 & 0.005 & 0.004 & 0.071 & .194 & .062 \\
\hline Honesty-Humility & & & & & & & & & 0.010 & 0.074 & 0.007 & .895 & 0.003 & 0.075 & 0.002 & .969 & .070 \\
\hline Emotionality & & & & & & & & & 0.150 & 0.077 & 0.110 & .051 & 0.179 & 0.079 & 0.131 & .024 & .059 \\
\hline Extraversion & & & & & & & & & 0.264 & 0.098 & 0.150 & .007 & 0.241 & 0.103 & 0.137 & .020 & .179 \\
\hline Agreeableness & & & & & & & & & 0.299 & 0.088 & 0.190 & .001 & 0.274 & 0.089 & 0.174 & .002 & .215 \\
\hline Conscientiousness & & & & & & & & & 0.090 & 0.088 & 0.056 & .309 & 0.072 & 0.088 & 0.045 & .416 & .101 \\
\hline $\begin{array}{l}\text { Openness to } \\
\text { Experience }\end{array}$ & & & & & & & & & -0.094 & 0.070 & -0.074 & .180 & -0.085 & 0.070 & -0.067 & .222 & -.088 \\
\hline Personal Burnout & & & & & & & & & & & & & 0.027 & 0.103 & 0.025 & .790 & -.171 \\
\hline $\begin{array}{c}\text { Work-Related } \\
\text { Burnout }\end{array}$ & & & & & & & & & & & & & -0.195 & 0.103 & -0.187 & .060 & -.227 \\
\hline $\begin{array}{l}\text { Client-Related } \\
\text { Burnout }\end{array}$ & & & & & & & & & & & & & 0.099 & 0.080 & 0.084 & .220 & -.139 \\
\hline$\Delta R^{2}$ & & & & & .004 & & & & .074 & & & & .017 & & & & \\
\hline$R^{2}$ & .100 & & & & .104 & & & & .178 & & & & .195 & & & & \\
\hline Sign. $\Delta R^{2}$ & $<.001$ & & & & .244 & & & & $<.001$ & & & & .110 & & & & \\
\hline
\end{tabular}

Individual-level analysis with $N=301$ individuals. $r_{c p}$ shows the Pearson-correlation between the dependent variable and the predictors. The $p$-values for $\Delta R^{2}$ for each model are obtained through the respective F-statistic, which is not displayed in the table

Table 4 Hierarchical regression analysis with the individual rating of cohesion as the dependent variable

\begin{tabular}{|c|c|c|c|c|c|c|c|c|c|c|c|c|c|c|c|c|c|}
\hline & \multicolumn{4}{|l|}{ Step 1} & \multicolumn{4}{|l|}{ Step 2} & \multicolumn{4}{|l|}{ Step 3} & \multicolumn{4}{|l|}{ Step 4} & \multirow[b]{2}{*}{$r_{c p}$} \\
\hline & B & $\mathrm{SE}(\mathrm{B})$ & $\beta$ & $p$ & $\mathrm{~B}$ & $\mathrm{SE}(\mathrm{B})$ & $\beta$ & $p$ & $\mathrm{~B}$ & $\mathrm{SE}(\mathrm{B})$ & $\beta$ & $p$ & B & $\mathrm{SE}(\mathrm{B})$ & $\beta$ & $p$ & \\
\hline Intercept & 1.011 & 0.234 & & .000 & 1.036 & 0.240 & & .000 & -1.108 & 0.620 & & .075 & -0.955 & 0.691 & & .168 & \\
\hline $\begin{array}{l}\text { Cohesion ratings } \\
\text { (self excluded) }\end{array}$ & 0.690 & 0.071 & 0.491 & .000 & 0.690 & 0.071 & 0.491 & .000 & 0.657 & 0.070 & 0.467 & .000 & 0.651 & 0.070 & 0.464 & .000 & .491 \\
\hline $\begin{array}{l}\text { Years of Work } \\
\text { Experience }\end{array}$ & & & & & -0.002 & 0.004 & -0.023 & .645 & -0.002 & 0.003 & -0.023 & .642 & -0.002 & 0.003 & -0.028 & .575 & -.020 \\
\hline Honesty-Humility & & & & & & & & & 0.045 & 0.067 & 0.034 & .505 & 0.046 & 0.069 & 0.035 & .503 & .079 \\
\hline Emotionality & & & & & & & & & 0.056 & 0.071 & 0.041 & .433 & 0.089 & 0.073 & 0.065 & .226 & .058 \\
\hline Extraversion & & & & & & & & & 0.279 & 0.089 & 0.158 & .002 & 0.274 & 0.094 & 0.155 & .004 & .199 \\
\hline Agreeableness & & & & & & & & & 0.312 & 0.080 & 0.197 & .000 & 0.294 & 0.081 & 0.186 & .000 & .220 \\
\hline Conscientiousness & & & & & & & & & 0.057 & 0.080 & 0.036 & .478 & 0.036 & 0.080 & 0.022 & .653 & .078 \\
\hline $\begin{array}{l}\text { Openness to } \\
\text { Experience }\end{array}$ & & & & & & & & & -0.082 & 0.064 & -0.065 & .200 & -0.073 & 0.064 & -0.058 & .251 & -.114 \\
\hline Personal Burnout & & & & & & & & & & & & & -0.002 & 0.094 & -0.002 & .986 & -.156 \\
\hline Work-Related Burnout & & & & & & & & & & & & & -0.166 & 0.094 & -0.159 & .079 & -.215 \\
\hline Client-Related Burnout & & & & & & & & & & & & & 0.134 & 0.073 & 0.114 & .067 & -.115 \\
\hline$\Delta R^{2}$ & & & & & .001 & & & & .078 & & & & .016 & & & & \\
\hline $\overrightarrow{R^{2}}$ & .241 & & & & .242 & & & & .320 & & & & .336 & & & & \\
\hline Sign. $\Delta R^{2}$ & $<.001$ & & & & .645 & & & & $<.001$ & & & & .074 & & & & \\
\hline
\end{tabular}

Individual-level analysis with $N=301$ individuals. $r_{c p}$ shows the Pearson-correlation between the dependent variable and the predictors. The $p$-values for $\Delta R^{2}$ for each model are obtained through the respective F-statistic, which is not displayed in the table 


\section{Discussion}

\section{Summary of Goals and Interpretation of Results}

The first goal of this study was to compare two approaches (direct and indirect) to conceptualizing and measuring psychological group characteristics to see if they measured similar constructs. These approaches describe different ways of creating group characteristics from either individual selfratings or individual group-characteristic ratings. The second goal was to further examine influences on individuals' perspectives on their ratings of group characteristics in the direct approach. We examined individual personality on the HEXACO dimensions, years of work experience, and work strain (operationalized as burnout symptoms) as predictors of group characteristic ratings.

In the present study, the scores obtained by applying the indirect approach did not predict the scores obtained by applying the direct approach, indicating that the two approaches might measure unrelated constructs. However, the question remains whether the missing associations are attributable to the constructs actually being unrelated or to differences between the modes of measurement.

Of course, the HEXACO-PI-R asks the respondents to rate themselves, while the GOCQ asks the respondents to rate their group. However, the inventories also differ with respect to their respective subscales. The HEXACO-PI-R assesses honesty-humility, emotionality, extraversion, agreeableness, conscientiousness, and openness to experience as fundamental traits in individuals (Ashton and Lee 2007). The GOCQ assesses cohesion and group openness as the fundamental characteristics of groups (Deckers et al. 2018). It can be argued that GOCQ cohesion may be comparable with HEXACO agreeableness and GOCQ group openness with HEXACO openness because of somewhat similar item content in the two inventories, e.g., "I tend to be lenient in judging other people" for HEXACO-PI-R agreeableness and "Everybody can freely bring up mistakes in the team" for GOCQ cohesion, and "I like people who have unconventional views" for HEXACO-PI-R openness to experience and "New ideas are considered in our team" for GOCQ group openness. However, the subscales differ of course in many other items and their primary focus. For instance, HEXACO openness is based more strongly on cultural and intellectual orientation than GOCQ group openness. With the presented findings, it remains uncertain to what extent the two inventories assess comparable or related constructs (independently of the respective approach to individual or group characteristics).

Therefore, it is also possible that the non-significant associations must simply be attributed to differences between the measures on the item and subscale levels - the measures may differ too much to detect similarities between the underlying constructs. Therefore, when interpreted conservatively, this study is only able to show that the indirect and direct approaches create unrelated group-level variables when operationalized through the HEXACO and GOCQ domains. However, for more conclusive evidence towards the two approaches being unrelated, future studies need to operationalize both approaches using the same items content.

Such a measure could be a re-wording of the HEXACO-PI$\mathrm{R}$ with the entire team as the referent. However, this is problematic, as many of the HEXACO-PI-R items turn out to lose their meaning when re-worded in such a way, as they are not applicable to the group level. Examples include the item "The first thing that I always do in a new place is to make friends", which is difficult to rate at all for an already established group, or "When I suffer from a painful experience, I need someone to make me feel comfortable", or "I've never really enjoyed looking through an encyclopedia", which are hardly applicable to the group level. We therefore decided on the GOCQ as the best available proxy for the "actual" latent group characteristics we aimed to measure. A specific direction for future research can be the development of an inventory that measures characteristics that are applicable to both individuals and groups to better compare the indirect and direct approaches.

The ICCs for the direct approach ranged from 23\% (group openness) to $37 \%$ (cohesion). ICCs between .2 and .4 are rarely found when multiple individuals rate the same characteristic and can be considered high (Hox 2010). Combined with our results, this seems to indicate that individual ratings of a group characteristic are always influenced to a larger degree by the raters' individual perspectives than by the presumed actual group characteristic itself.

Only extraversion and agreeableness were significant predictors of individual ratings of group openness and cohesion beyond the influence of the group, and all predictions were positive (e.g., higher extraversion was associated with a higher rating of cohesion). Higher agreeableness might lead an individual to avoid conflict situations (McCrae and Costa Jr. 1999), therefore missing the type of group behaviors that might negatively affect ratings of group openness and cohesion. Higher extraversion generally leads to more social interaction with a tendency to seek positive interactions (McCrae and Costa Jr. 1999), allowing an individual to more accurately rate group openness and cohesion and to rate his or her group more positively.

Years of work experience did not significantly predict ratings of group characteristics. This finding was expected, given that years of work experience was highly correlated with age, and age was shown to not predict individual ratings of cohesion (Glass and Benshoff 2002).

The three facets of burnout did not significantly predict ratings of group characteristics. High work strain (manifested as burnout symptoms) might be a phenomenon that is more "contained" within the individual, and it might be that individuals do not let burnout symptoms affect how they view their team. 
It is possible that the similar relationships that we observed for both group openness and cohesion in strength and direction of the predictions reflect members' positive attitudes towards their group. Future research could include an explicit or implicit measure of positive and negative affect to examine such a possible moderation effect.

Overall, only $19.5 \%$ of group openness rating variance and $33.6 \%$ of cohesion rating variance was explained by the variables we included. Other factors likely influence how an individual perceives and rates his or her team, but such factors have not been explored in past research and were not included in our study.

This study was conducted in a workplace setting. Although group openness and cohesion are hypothesized to be applicable to all groups, group members in different types of groups might rate them differently. On the other hand, this sample comes with high ecological validity: Work teams are not artificially created as groups in laboratory studies often are, and instead share a longer and more intimate history, and frequently spend multiple hours per day together.

\section{Limitations}

Most importantly, we operationalized the indirect and direct measurements through instruments containing different items and conceptually different subscales. This offers an alternative explanation for the absence of significant connections between the approaches, as discussed above. Further evidence for connections between the approaches, or a lack thereof, could be obtained through the development of a more parallel measure that is applicable to both individuals and groups, e.g., by using the same or very similar items for both self- and group ratings (e.g.: "Changes make me / us uncomfortable").

We cannot test to what extent the findings of this study translate to very small teams (e.g., with five or less members), as the smallest team in our sample consisted of seven members. In the initial publication of the GOCQ (Deckers et al. 2018), it has been shown that cohesion ratings differ only between medium-sized teams (15-22 members) and large teams (2460 members), and that group openness ratings are unaffected by team size. GOCQ ratings in this study might therefore be applicable to small teams, but it is unknown to what extent the indirect approach variables are affected by team size.

It was rarely possible for us to recruit full teams (due to organizational and time constraints); therefore, we essentially sampled team members per team. Results might differ when full teams are assessed, especially for the indirect approach, as recruiting full teams should lead to a more accurate result when group means are calculated. However, standard deviations in each team for both the direct and the indirect approach measures did not significantly correlate with the percentage of assessed team members, indicating that, at least for dispersion measures, assessing a larger portion of the teams would likely not have affected the results.
Related to this, we did not examine minima and maxima in the indirect approach, as we could not ensure that the team member with the highest individual characteristic value was part of the sample.

As this study was neither longitudinal nor experimental in its nature, it is not possible to draw causal conclusions from it. Finally, it is possible that the responses obtained through the instruments are affected by common method bias, although the many insignificant correlations between the variables provide some evidence against this.

This study was conducted in a workplace setting, so the results obtained here might not be applicable to other types of groups. Even though Group Openness and Cohesion are hypothesized to be applicable to all groups, group members in different types of groups might rate them in different ways. Related to this, the work setting might make it less likely for groups to contain individuals with similar individual personality characteristics, compared with, for example, friendship groups. In a work setting, the members are often assigned to a group by supervisors, and thus, the group members most likely do not play a role in the decision.

The findings presented in Table 2 are based on team averages with a sample size of $N=54$ teams. With this relatively low sample size, a satisfactory statistical power of $1-\beta>0.8$ can only be reached for medium to large effects $\left(f^{2}>0.28\right)$. It is therefore possible that small population-level effects could not have been detected with this sample.

Finally, for a comparison of this study with past research involving the Big Five personality traits applied to the group level, differences between the Five Factor and HEXACO models must be taken into consideration.

\section{Conclusion}

We recommend that researchers who are interested in grouplevel characteristics use a direct measure to assess these characteristics by having all group members rate the group directly. However, if the data show that there is a lack of overlap between the group members in rating this characteristic, the individual perspective of the group members should be examined further. Based on this study, important goals of future research should be to better understand how individual ratings of group characteristics are formed, and how individual-level characteristics can be used to construct meaningful grouplevel characteristics.

Additionally, future research concerned with comparisons between the direct and the indirect approaches to group characteristics should include external criteria of validity for both. The results of this study, along with the results of the cited meta-analyses, provide some evidence against the validity of the indirect approach, however, more research is needed for meaningful conclusions about it. 
This study also provides an interesting avenue for potential new ways to characterize groups through member ratings: The approach of excluding variance explained by the ratings of the other group members from each individual rater could potentially be reversed to obtain a better proxy for the actual latent group characteristic than simple group means could ever be.

Overall, this study provides theoretical and practical implications for both direct and indirect conceptualizations of group characteristics, and therefore for researches using either approach to characterize groups and assess connections with other group-level phenomena.

Authors Contributions Mr. Marius Deckers, B. Sc., M. Sc. Data collection, curation, analysis, and interpretation, Methodology, Manuscript Writing. Mr. Tobias Altmann, PhD Funding acquisition, Methodology, Project administration, Supervision, Manuscript Reviewing \& Editing. Mr. Marcus Roth, Univ.-Prof., PhD Funding acquisition, Methodology, Project administration, Supervision, Manuscript Reviewing \& Editing.

Funding Open Access funding provided by Projekt DEAL. This work was supported by the Federal Ministry of Education and Research (BMBF) [grant number: 02L14A150]. The BMBF was not involved in study design, data collection, data analysis, data interpretation, the writing of this report, and in the decision to submit this article for publication.

\section{Compliance with Ethical Standards}

Conflict of Interest On behalf of all authors, the corresponding author states that there is no conflict of interest.

Ethical Approval All procedures performed in this study involving human participants were in accordance with the ethical standards of the institutional research committees and with the 1964 Helsinki declaration and its later amendments or comparable ethical standards. Three ethics committees approved all aspects of the study: The „Ethikkommission der Abteilung Informatik und Angewandte Kognitionswissenschaft der Fakultät für Ingenieurwissenschaften der Universität Duisburg-Essen "(no reference number given by the committee), the "Ethikkommission der Medizinischen Fakultät der Universität zu Köln" (no reference number given by the committee), and the "Ethik-Kommission - Medizinische Fakultät Bonn" (reference number: 154/16).

This article does not contain any studies with animals performed by any of the authors.

Informed Consent Informed Consent Has Been Given by all Participants in the Study, and there Is no Identifying Information in this Manuscript or the Data, which Are Available on Reasonable Request from the Authors

Open Access This article is licensed under a Creative Commons Attribution 4.0 International License, which permits use, sharing, adaptation, distribution and reproduction in any medium or format, as long as you give appropriate credit to the original author(s) and the source, provide a link to the Creative Commons licence, and indicate if changes were made. The images or other third party material in this article are included in the article's Creative Commons licence, unless indicated otherwise in a credit line to the material. If material is not included in the article's Creative Commons licence and your intended use is not permitted by statutory regulation or exceeds the permitted use, you will need to obtain permission directly from the copyright holder. To view a copy of this licence, visit http://creativecommons.org/licenses/by/4.0/.

\section{References}

Anderson, N. R., \& West, M. A. (1998). Measuring climate for work group innovation: Development and validation of the team climate inventory. Journal of Organizational Behavior, 19(3), 235-258. https://doi.org/10.1002/(sici)1099-1379(199805)19:3<235::aidjob837>3.3.co;2-3.

Ashton, M. C., \& Lee, K. (2007). Empirical, theoretical, and practical advantages of the HEXACO model of personality structure. Personality and Social Psychology Review, 11(2), 150-166. https://doi.org/10.1177/1088868306294907.

Ashton, M. C., \& Lee, K. (2008a). The HEXACO model of personality structure and the importance of the $\mathrm{H}$ factor. Social and Personality Psychology Compass, 2(5), 1952-1962. https://doi.org/10.1111/j. 1751-9004.2008.00134.x.

Ashton, M. C., \& Lee, K. (2008b). The prediction of honesty-humilityrelated criteria by the HEXACO and five-factor models of personality. Journal of Research in Personality, 42(5), 1216-1228. https:// doi.org/10.1016/j.jrp.2008.03.006.

Ashton, M. C., \& Lee, K. (2009). The HEXACO-60: A short measure of the major dimensions of personality. Journal of Personality Assessment, 91(4), 340-345. https://doi.org/10.1080/ 00223890902935878.

Ashton, M. C., \& Lee, K. (2019). How well do big five measures capture HEXACO scale variance? Journal of Personality Assessment, 101(6), 567-573. https://doi.org/10.1080/00223891.2018.1448986.

Ashton, M. C., Lee, K., Marcus, B., \& De Vries, R. E. (2007). German lexical personality factors: Relations with the HEXACO model. European Journal of Personality, 21(1), 23-43. https://doi.org/10. 1002/per.597.

Barrick, M. R., \& Mount, M. K. (1991). The big five personality dimensions and job performance: A meta-analysis. Personnel Psychology, 44(1), 1-26.

Barrick, M. R., Stewart, G. L., Neubert, M. J., \& Mount, M. K. (1998). Relating member ability and personality to work-team processes and team effectiveness. Journal of Applied Psychology, 83(3), 377-391. https://doi.org/10.1037/0021-9010.83.3.377.

Barry, B., \& Stewart, G. L. (1997). Composition, process, and performance in self-managed groups: The role of personality. Journal of Applied Psychology, 82(1), 62-78.

Bell, S. T. (2007). Deep-level composition variables as predictors of team performance: A meta-analysis. Journal of Applied Psychology, 92(3), 595-615. https://doi.org/10.1037/0021-9010.92.3.595.

Bjornberg, A., \& Nicholson, N. (2007). The family climate scales - development of a new measure for use in family business research. Family Business Review, 20(3), 229-246. https://doi.org/10.1111/j. 1741-6248.2007.00098.x.

Bond, M. H., \& Shiu, W. Y. F. (1997). The relationship between a Group's personality resources and the two dimensions of its group process. Small Group Research, 28(2), 194-217. https://doi.org/10. 1177/1046496497282002.

Carron, A. V., \& Spink, K. S. (1995). The group size-cohesion relationship in minimal groups. Small Group Research, 26(1), 86-105.

Carron, A. V., Widmeyer, W. N., \& Brawley, L. R. (1985). The development of an instrument to assess cohesion in sport teams: The group environment questionnaire. Journal of Sport Psychology, 7(3), 244-266.

Chan, D. (1998). Functional relations among constructs in the same content domain at different levels of analysis: A typology of composition models. Journal of Applied Psychology, 83(2), 234-246. https://doi.org/10.1037//0021-9010.83.2.234.

Cheng, C., Bartram, T., Karimi, L., \& Leggat, S. (2016). Transformational leadership and social identity as predictors of team climate, perceived quality of care, burnout and turnover intention 
among nurses. Personnel Review, 45(6), 1200-1216. https://doi.org/ 10.1108/pr-05-2015-0118.

Cohen, J. (1992). A power primer. Psychological Bulletin, 112(1), $155-159$.

Dackert, I. (2010). The impact of team climate for innovation on wellbeing and stress in elderly care. Journal of Nursing Management, 18(3), 302-310. https://doi.org/10.1111/j.1365-2834.2010.01079.x.

Dang, C. C., \& Ilgen, D. R. (2006). Team personality: A dynamic, contextualized view. Zeitschrift für Personalpsychologie, 5(4), 177185. https://doi.org/10.1026/1617-6391.5.4.177.

Deckers, M., Altmann, T., \& Roth, M. (2018). Conceptualizing and measuring group openness and cohesion as dimensions of group personality. Psychology, 09(01), 80-100. https://doi.org/10.4236/psych. 2018.91006.

Durkin, M., Beaumont, E., Hollins Martin, C. J., \& Carson, J. (2016). A pilot study exploring the relationship between self-compassion, selfjudgement, self-kindness, compassion, professional quality of life and wellbeing among UK community nurses. Nurse Education Today, 46, 109-114. https://doi.org/10.1016/j.nedt.2016.08.030.

Ekehammar, B., Akrami, N., Gylje, M., \& Zakrisson, I. (2004). What matters most to prejudice: Big five personality, social dominance orientation, or right-wing authoritarianism? European Journal of Personality, 18(6), 463-482. https://doi.org/10.1002/per.526.

Evans, C. R., \& Dion, K. L. (2012). Group cohesion and performance: A meta-analysis. Small Group Research, 43(6), 690-701. https://doi. org/10.1177/1046496412468074.

Eys, M. A., Lougheed, T., Bray, S. R., \& Carron, A. V. (2009). Development of a cohesion questionnaire for youth: The youth sport environment questionnaire. Journal of Sport and Exercise Psychology, 31(3), 390-408.

Glass, J. S., \& Benshoff, J. M. (2002). Facilitating group cohesion among adolescents through challenge course experiences. The Journal of Experiential Education, 25(2), 268-277.

Glisson, C., \& James, L. R. (2002). The cross-level effects of culture and climate in human service teams. Journal of Organizational Behavior, 23(6), 767-794. https://doi.org/10.1002/job.162.

Goh, T. T., Eccles, M. P., \& Steen, N. (2009). Factors predicting team climate, and its relationship with quality of care in general practice. BMC Health Services Research, 9, 138. https://doi.org/10.1186/ 1472-6963-9-138.

Gully, S. M., Devine, D. J., \& Whitney, D. J. (2012). A meta-analysis of cohesion and performance: Effects of level of analysis and task interdependence. Small Group Research, 43(6), 702-725. https:// doi.org/10.1177/1046496412468069.

Halfhill, T., Nielsen, T. M., Sundstrom, E., \& Weilbaecher, A. (2005a). Group personality composition and performance in military service teams. Military Psychology, 17(1), 41-54. https://doi.org/10.1207/ s15327876mp1701_4.

Halfhill, T., Sundstrom, E., Lahner, J., Calderone, W., \& Nielsen, T. M. (2005b). Group personality composition and group effectiveness: An integrative review of empirical research. Small Group Research, 36(1), 83-105. https://doi.org/10.1177/1046496404268538.

Hellriegel, D., \& Slocum, J. W. (1974). Organizational climate: Measures, research and Contengencies. Academy of Management Journal, 17(2), 255-280.

Homan, A. C., Hollenbeck, J. R., Humphrey, S. E., Van Knippenberg, D., Ilgen, D. R., \& Van Kleef, G. A. (2008). Facing differences with an open mind: Openness to experience, salience of intragroup differences, and performance of diverse work groups. Academy of Management Journal, 51(6), 1204-1222.

Hox, J. J. (2010). Multilevel Analysis: Techniques and Applications. New York: Routledge.

Hurtz, G. M., \& Donovan, J. J. (2000). Personality and job performance: The big five revisited. Journal of Applied Psychology, 85(6), 869879. https://doi.org/10.1037/0021-9010.85.6.869.
Kivimaki, M., Vanhala, A., Pentti, J., Lansisalmi, H., Virtanen, M., Elovainio, M., \& Vahtera, J. (2007). Team climate, intention to leave and turnover among hospital employees: Prospective cohort study. BMC Health Services Research, 7, 170. https://doi.org/10. 1186/1472-6963-7-170.

Kristensen, T. S., Borritz, M., Villadsen, E., \& Christensen, K. B. (2005). The Copenhagen burnout inventory: A new tool for the assessment of burnout. Work and Stress, 19(3), 192-207. https://doi.org/10. 1080/02678370500297720.

Kurdek, L. A., Fine, M. A., \& Sinclair, R. J. (1995). School adjustment in sixth graders: Parenting transitions, family climate, and peer norm effects. Child Development, 66(2), 430-445.

Law, T., Lee, K. Y., Ho, F. N., Vlantis, A. C., van Hasselt, A. C., \& Tong, M. C. (2012). The effectiveness of group voice therapy: A group climate perspective. Journal of Voice, 26(2), e41-e48. https://doi. org/10.1016/j.jvoice.2010.12.003.

Lee, K., \& Ashton, M. C. (2008). The HEXACO personality factors in the indigenous personality lexicons of English and 11 other languages. Journal of Personality, 76(5), 1001-1054. https://doi.org/ 10.1111/j.1467-6494.2008.00512.x.

Leone, L., Desimoni, M., \& Chirumbolo, A. (2012). HEXACO, social worldviews and socio-political attitudes: A mediation analysis. Personality and Individual Differences, 53(8), 995-1001. https:// doi.org/10.1016/j.paid.2012.07.016.

MacKenzie, K. R., \& Tschuschke, V. (1993). Relatedness, group work and outcome in long-term inpatient psychotherapy groups. Journal of Psychotherapy Practice and Research, 2(2), 147-156.

McCrae, R. R., \& Costa Jr., P. T. (1999). A five-factor theory of personality. Handbook of personality: Theory and research, 2, 139-153.

Neuman, G. A., Wagner, S. H., \& Christiansen, N. D. (1999). The relationship between work-team personality composition and the job performance of teams. Group \& Organization Management, 24(1), 28-45.

Peeters, M. A. G., van Tuijl, H. F. J. M., Rutte, C. G., \& Reymen, I. M. M. J. (2006). Personality and team performance: A meta-analysis. European Journal of Personality, 20(5), 377-396. https://doi.org/ $10.1002 /$ per.588

Roth, M. (2002). Entwicklung und Überprüfung einer Kurzform der Familienklimaskalen für Jugendliche (K-FKS-J) [Development and Evaluation of a Short-Form of the German K-FKS-J]. Zeitschrift für Differentielle und Diagnostische Psychologie, 23(2), 225-234. https://doi.org/10.1024//0170-1789.23.2.225.

Shoda, Y., LeeTiernan, S., \& Mischel, W. (2002). Personality as a dynamical system: Emergence of stability and distinctiveness from intra and interpersonal interactions. Personality and Social Psychology Review, 6(4), 316-325. https://doi.org/10.1207/s15327957pspr0604_06.

Turner, R. N., Dhont, K., Hewstone, M., Prestwich, A., \& Vonofakou, C. (2014). The role of personality factors in the reduction of intergroup anxiety and amelioration of Outgroup attitudes via intergroup contact. European Journal of Personality, 28(2), 180-192. https://doi. org/10.1002/per.1927.

van Vianen, A. E. M., \& De Dreu, C. K. W. (2001). Personality in teams: Its relationship to social cohesion, task cohesion, and team performance. European Journal of Work and Organizational Psychology, 10(2), 97-120. https://doi.org/10.1080/13594320143000573.

Visser, B. A., \& Pozzebon, J. A. (2013). Who are you and what do you want? Life aspirations, personality, and well-being. Personality and Individual Differences, 54(2), 266-271. https://doi.org/10.1016/j. paid.2012.09.010.

Widmeyer, W., Brawley, L. R., \& Carron, A. V. (1990). The effects of group size in sport. Journal of Sport and Exercise Psychology, 12(2), 177-190.

Publisher's Note Springer Nature remains neutral with regard to jurisdictional claims in published maps and institutional affiliations. 